\title{
Conferring extracellular matrix affinity enhances local therapeutic efficacy of anti- TNF- $a$ antibody in a murine model of rheumatoid arthritis
}

Kiyomitsu Katsumata ${ }^{1,2}$, Jun Ishihara', Kazuto Fukunaga ${ }^{1,3}$, Ako Ishihara', Eiji Yuba $^{1,4}$, Erica Budina ${ }^{1}$ and Jeffrey A. Hubbell ${ }^{1,5^{*}}$ (D)

\begin{abstract}
Background: Although disease in a majority of rheumatoid arthritis (RA) patients is often initially limited to one or a few joints, currently approved medications including anti-tumor necrosis factor-a antibody (a-TNF) are injected systemically. Given that a-TNF systemic injection typically does not cure RA and involves risk of treatment-related adverse events, one possible approach to enhance therapeutic efficacy and reduce a-TNF systemic exposure is to retain the antibodies in arthritic joints after local administration. The aim of this study was to evaluate the approach of conferring extracellular matrix (ECM) binding affinity to a-TNF antibodies in a RA model.

Methods: a-TNF was chemically conjugated with a promiscuous ECM-binding peptide derived from placenta

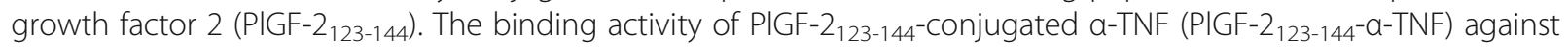
ECM proteins was assessed by ELISA and by immunostaining on human cartilage specimens. The effect of conjugation on antibody function was assessed as a neutralizing activity against osteoclast differentiation. Retention at the injection site and therapeutic efficacy of PIGF-2 $123-144^{-\alpha-T N F}$ were tested in a collagen antibody-induced arthritis (CAIA) model in the mouse.

Results: PIGF-2123-144 peptide conjugation conferred a-TNF with affinity to ECM proteins without impairment of antigen recognition. PIGF-2 $123-144-\mathrm{a}-$ TNF locally injected at a paw in the CAIA model was retained for at least $96 \mathrm{~h}$ at the injection site, whereas unmodified a-TNF was dispersed rapidly after injection. Local treatment with unmodified a-TNF did not suppress the arthritis score relative to isotype controls. By contrast, local administration of PIGF2123-144-a-TNF suppressed arthritis development almost completely in the treated paw even at a 1000x lower dose. Conclusion: These data demonstrate that retention of a-TNF in arthritic joints can suppress arthritis development and enhance therapeutic efficacy. This simple bioengineering approach of ECM-binding peptide conjugation offers a powerful and clinically translational approach to treat RA.
\end{abstract}

Keywords: Extracellular matrix binding peptide, PIGF-2 $223-144$ peptide, Bioengineering, Joint targeting, Localized therapy, Collagen antibody-induced arthritis model

\footnotetext{
* Correspondence: jhubbell@uchicago.edu

${ }^{1}$ Pritzker School of Molecular Engineering, University of Chicago, Chicago, IL 60637, USA

${ }^{5}$ Committee on Immunology, University of Chicago, Chicago, IL 60637, USA

Full list of author information is available at the end of the article
}

(c) The Author(s). 2019 Open Access This article is distributed under the terms of the Creative Commons Attribution 4.0 International License (http://creativecommons.org/licenses/by/4.0/), which permits unrestricted use, distribution, and reproduction in any medium, provided you give appropriate credit to the original author(s) and the source, provide a link to the Creative Commons license, and indicate if changes were made. The Creative Commons Public Domain Dedication waiver (http://creativecommons.org/publicdomain/zero/1.0/) applies to the data made available in this article, unless otherwise stated. 


\section{Background}

Rheumatoid arthritis (RA) is a chronic, progressive autoimmune disease characterized by the formation of hyperplastic synovial pannus tissue, which causes joint destruction [1, 2]. Biological therapies to block cytokine signals in the human body, such as anti-TNF $\alpha$ ( $\alpha$-TNF) and anti-IL-6 receptor antibodies, are powerful approaches for treating RA [3-6]. However, currently approved medications show incomplete response in terms of joint damage by persistent synovitis even in patients in clinical remission, and they have the possibility of significant side effects by suppressing systemic immunity [7-11]. Arthritis is classified as monoarthritis, oligoarthritis, and polyarthritis, by the numbers of joints in which symptoms appear. Many polyarthritic disorders initially present as a monoarthritis. In patients with recent-onset arthritis, monoarticular involvement (38.3\%) is more common than oligoarticular $(34.1 \%)$ or polyarticular $(24.6 \%)$ disease [12]. Considering the worse prognosis of polyarticular arthritis, early intervention is critical to maximize outcomes $[12,13]$.

Direct intra-articular administration of drugs is a reasonable approach to enhance their local efficacy and reduce systemic adverse effects and is relevant for the treatment of monoarthritis and oligoarthritis. However, drugs injected into the joint are rapidly cleared via lymphatics or sub-synovial capillaries in the absence of a retention strategy [14]. In addition, the clearance rate of macromolecules from inflamed joints is increased in patients with RA due to enhanced drainage from the joint space by greater synovial lymph flow [15]. Although intraarticular $\alpha$-TNF injections have been shown to be well tolerated and improve clinical signs in RA patients in small clinical trials, the therapeutic effect was limited and transient $[16,17]$. These results indicate that intra-articular injection is a promising approach for effective therapy, but requires an approach for local tissue retention.

Heparin-binding domains (HBDs) derived from growth factors (GFs) bind to HBDs derived from a variety of extracellular matrix (ECM) proteins [18-22]. By screening the binding of GFs to a variety of ECM proteins, we have discovered that the HBD of placenta growth factor-2 (PlGF-2 $123-144)$ has an exceptionally high affinity for multiple ECM proteins [23]. Chemical conjugation of the PlGF-2 ${ }_{123-144}$ peptide to immune checkpoint blockade and immune agonist antibodies enhanced antibody retention within tumors when injected near the tumor, improving therapeutic efficacy and safety by limiting systemic exposure [24, 25].

Here, we have hypothesized that utilizing ECMbinding technology for prolonged tissue retention would improve the ability of an anti-inflammatory cytokine antibody to effectively suppress RA development. We engineered $\alpha$-TNF conjugated with PlGF-2123-144 peptide for RA therapy. We tested whether the enhanced retention of $\alpha$-TNF in tissue surrounding the joints would improve its local efficacy against arthritis development.

\section{Methods}

Synthesis of peptide-conjugated antibody

The synthesis of PlGF-2 $123-144^{-\alpha-T N F}$ was performed as described previously [24]. Rat anti-mouse TNF $\alpha$ antibody (clone XT3.11, Bio X Cell, West Lebanon, NH, USA; or clone MP6-XT22, BioLegend, San Diego, CA, USA) was incubated with an excess amount of sulfoSMCC or SM (PEG) 4 crosslinker (Thermo Fisher Scientific, Waltham, MA, USA) for $30 \mathrm{~min}$ at room temperature. Unreacted crosslinker was removed using a Zeba spin desalting column (Thermo Fisher Scientific), and then 15-fold molar excess of PlGF-2123-144 peptide (RRRPKGRGKRRREKQRPTDCHL) was added and reacted for $1 \mathrm{~h}$ at room temperature for conjugation to the thiol moiety on the $\mathrm{C}$ residue. The peptide had been synthesized with $>95 \%$ purity by Genscript (Piscataway, NJ, USA).

\section{Sodium dodecyl sulfate-polyacrylamide gel electrophoresis}

Sodium dodecyl sulfate-polyacrylamide gel electrophoresis (SDS-PAGE) was performed on 4-20\% gradient gels (Bio-Rad, Hercule, CA, USA) after $\alpha$-TNF was reduced with $10 \mathrm{mM}$ DTT. After electrophoresis, gels were stained with SimplyBlue SafeStain (Thermo Fisher Scientific) according to the manufacturer's instruction. Gel images were acquired with the ChemiDoc XRSp system (Bio-Rad).

\section{Matrix-assisted laser desorption/ionization-time-of-flight mass spectrometry}

Antibodies were analyzed by Matrix-assisted laser desorption/ionization-time-of-flight mass spectrometry (MALDI-TOF MS) using a Bruker Ultraflextreme MALDI TOF/TOF instrument. All spectra were collected with acquisition software Bruker flexControl ${ }^{\mathrm{Tm}}$ and processed with analysis software Bruker flexAnalysis ${ }^{\mathrm{Tm}}$. First, a saturated solution of the matrix, $\alpha$-cyano-4hydroxycinnamic acid (MilliporeSigma, Billerica, MA, USA), was prepared in 50:50 (v/v) acetonitrile:(1\% trifluoroacetic acid in water) as a solvent. The analyte in phosphate-buffered saline (PBS; $5 \mu \mathrm{L}, 0.1 \mathrm{mg} / \mathrm{mL}$ ) and the matrix solution $(25 \mu \mathrm{L})$ were then mixed, and $1 \mu \mathrm{L}$ of that mixture was deposited on the MTP 384 ground steel target plate. The drop was allowed to dry in a nitrogen gas flow, which resulted in the formation of uniform sample/matrix co-precipitate. All samples were analyzed using the high mass linear positive mode method with 5000 laser shots at a laser intensity of $75 \%$. 
The measurements were externally calibrated at three points with a mix of carbonic anhydrase, phosphorylase $\mathrm{B}$, and bovine serum albumin.

\section{Enzyme-linked immunosorbent assay}

Ninety-six well Enzyme-linked immunosorbent assay (ELISA) plates (Greiner Bio-One, Monroe, NC, USA) were coated with recombinant human ECM proteins $(10 \mu \mathrm{g} / \mathrm{mL})$ : fibronectin (MilliporeSigma), decorin (Abcam, Cambridge, MA, USA), collagen I (MilliporeSigma), collagen II (MilliporeSigma), collagen III (MilliporeSigma), or collagen IV (MilliporeSigma); or $1 \mu \mathrm{g} / \mathrm{mL}$ of recombinant murine TNFa (PeproTech, Princeton, NJ, USA) in PBS overnight at $37^{\circ} \mathrm{C}$, followed by blocking with $2 \%$ BSA in PBS with $0.05 \%$ Tween 20 (PBS-T) for $1 \mathrm{~h}$ at room temperature. Then, wells were washed with PBS-T and further incubated with test antibody $(100 \mu \mathrm{g} /$ $\mathrm{mL}$ each) for $1 \mathrm{~h}$ at room temperature. After three washes with PBS-T, wells were incubated for $1 \mathrm{~h}$ at room temperature with horseradish peroxidase (HRP)-conjugated antibody against rat IgG (Jackson ImmunoResearch, Westgrove, PA, USA). After washes, bound antibodies were detected with tetramethylbenzidine substrate by measurement of absorbance at $450 \mathrm{~nm}$ with the subtraction of absorbance at $570 \mathrm{~nm}$.

\section{Immunohistochemistry}

Frozen sections of cartilage from an osteoarthritis patient were purchased from OriGene Technologies (Rockville, MD, USA). The sections were blocked with $2 \%$ FBS in PBS overnight at room temperature. The sections were incubated with primary antibodies for $3 \mathrm{~h}$ at room temperature. Either $50 \mu \mathrm{g} / \mathrm{mL}$ of rat $\alpha$-TNF or equimolar PlGF-2 $123-144^{-} \alpha-T N F, 5 \mu \mathrm{g} / \mathrm{mL}$ of rabbit anti-human collagen II antibody (Abcam), or $25 \mu \mathrm{g} / \mathrm{mL}$ of mouse antihuman decorin antibody (R\&D Systems, Minneapolis, MN, USA) were used as primary antibodies. After incubating with the fluorescently tagged secondary antibodies, slides were covered with ProLong Gold Antifade Mountant with DAPI (Thermo Fisher Scientific). The images were scanned with a Pannoramic digital slide scanner (3DHistech, Budapest, Hungary) and analyzed using a Pannoramic Viewer software (3DHistech).

\section{Cells}

The murine macrophage-like cell line RAW264.7, an osteoclast precursor, was obtained from the American Type Culture Collection (ATCC; Rockville, MD, USA). Cells were cultured in Dulbecco's modified Eagle's medium (DMEM; Invitrogen, Carlsbad, CA, USA) supplemented with 10\% FBS (Invitrogen), $100 \mathrm{U} / \mathrm{mL}$ of penicillin (Biological Industries, Cromwell, CT, USA), and $100 \mu \mathrm{g} / \mathrm{mL}$ of streptomycin (Biological Industries) at $37^{\circ} \mathrm{C}$ in a humidified $5 \% \mathrm{CO}_{2}$ atmosphere.

\section{Osteoclast differentiation from RAW264.7 cells}

RAW264.7 cells were seeded on $60-\mathrm{mm}$ dishes at a density of $3 \times 10^{6}$ cells per well and cultured for 7 days in the presence of $50 \mathrm{ng} / \mathrm{mL}$ of recombinant mouse TNF $\alpha$ (Insight Biotechnology, Middlesex, UK), $10 \mathrm{ng} / \mathrm{mL}$ of recombinant mouse receptor activator of nuclear factor $\mathrm{\kappa B}$ ligand (RANKL; PeproTech), and 50 to $1000 \mathrm{ng} /$ $\mathrm{mL}$ of test antibody. The cells were then washed with PBS and stained using Acid Phosphatase, Leukocyte (TRAP) kit (MilliporeSigma) according to the manufacture's instruction. TRAP-positive multinucleated cells having three or more nuclei were considered as osteoclasts, and their number was counted in each well. Percent inhibition was calculated from a ratio of the number of osteoclasts in each treatment to that in the untreated control. The 50\% inhibitory concentration $\left(\mathrm{IC}_{50}\right)$ values were obtained by nonlinear regression analysis (GraphPad Prism Software, LaJolla, CA, USA).

\section{Mice}

$\mathrm{Balb} / \mathrm{c}$ and athymic nude mice at 8 to 9 weeks of age were obtained from the Jackson Laboratory (Bar Harbor, ME, USA). Experiments were performed with approval from the Institutional Animal Care and Use Committee of the University of Chicago (Chicago, IL, USA).

\section{Collagen antibody-induced arthritis model}

Arthritis was induced in Balb/c mice by intraperitoneal injection of anti-collagen antibody cocktail at $1.5 \mathrm{mg}$ (Chondrex, Redmond, Washington, USA) on day -3 , followed by intraperitoneal injection of LPS at $50 \mu \mathrm{g}$ (Chondrex) on day 0 . On the day of LPS injection, mice were injected at the left hind footpad with PBS, $15 \mu \mathrm{g}$ of PIGF-2123-144 peptide (theoretical equivalent amount of peptides within $100 \mu \mathrm{g}$ of PlGF-2 $\left.123-144^{-} \alpha-\mathrm{TNF}\right), 100 \mu \mathrm{g}$ of control IgG (rat IgG1 isotype control, Bio X Cell), $100 \mu \mathrm{g}$ of unmodified $\alpha$-TNF, or 0.1 or $1 \mu \mathrm{g}$ of PlGF$2123-144^{-} \alpha-T N F$. Joint swelling in the left and right hind paws was scored daily as described elsewhere [26]. The left hind paws of the collagen antibody-induced arthritis (CAIA) mice were fixed in 10\% neutral formalin (MilliporeSigma), decalcified in Decalcifer II (Leica Microsystems Inc., Buffalo Grove, IL, USA), and then embedded in paraffin. The paraffin-embedded paws were sliced at $5 \mu \mathrm{m}$ thickness and stained with hematoxylin and eosin (H\&E). The images were scanned with a Pannoramic digital slide scanner and analyzed using a Pannoramic Viewer software.

\section{In vivo bio-distribution study}

$\alpha$-TNF was fluorescently labeled using sulfo-Cyanine 7 (Cy7) NHS ester (Lumiprobe, Broward, FL, USA) according to the manufacture's instruction. PlGF-2 2 123-144 peptide that was labeled with $\mathrm{Cy} 7$ in its $\mathrm{N}$-terminus was 
chemically synthesized with $>90 \%$ purity by Thermo Fisher Scientific. Cy7-labeled PIGF-2123-144 was conjugated to $\alpha$-TNF as described above. The Cy7 labeled antibody at a dose of $20 \mu \mathrm{g}$ was injected at the left hind footpad of CAIA mice or athymic nude mice. The fluorescence level was measured using the Xenogen IVIS Imaging System 100 (Xenogen, Alameda, CA, USA) under the following conditions: f/stop: 2; optical filter excitation $745 \mathrm{~nm}$; excitation $800 \mathrm{~nm}$; exposure time: $5 \mathrm{~s}$; small binning. Retention rates of the injected antibody immediately after the injection and that at $168 \mathrm{~h}$ after the injection were defined as $100 \%$ and $0 \%$, respectively.

\section{Measurement of plasma concentration of the injected antibodies}

CAIA mice received $1 \mu \mathrm{g}$ of PlGF- $2_{123-144^{-} \alpha-\mathrm{TNF} \text { or }}$ $100 \mu \mathrm{g}$ of unmodified $\alpha$-TNF. Blood was collected from the tail vein with a heparinized capillary at $24,48,72$, and $96 \mathrm{~h}$ after the injection, and plasma was obtained by centrifugation. The injected antibodies in plasma were measured by ELISA as described above.

\section{Statistical analysis}

Statistical analyses were performed using GraphPad Prism software, and $P<0.05$ was considered statistically significant. Binding activities against ECM proteins were analyzed using Student's $t$ test for comparisons between PlGF-2 $123-144-\alpha-T N F$ and unmodified $\alpha$-TNF. The retention effect of PlGF-2 $123-144-\alpha-T N F$ was analyzed in the area under the percent of retention at the injection sitetime curve from 0 to $96 \mathrm{~h}\left(\mathrm{AUC}_{0-96 \mathrm{~h}}\right)$ compared with unmodified $\alpha$-TNF using Student's t-test. The $\mathrm{AUC}_{0-96 \mathrm{~h}}$ of plasma concentration was analyzed using Student's ttest for comparisons between PlGF-2 $123-144-\alpha-T N F$ and unmodified $\alpha$-TNF. To compare the efficacy of PlGF2 123-144- $\alpha$-TNF with unmodified $\alpha$-TNF, the data on day 6 were analyzed using Tukey's multiple comparison test.

\section{Results}

PIGF-2 123-144 peptide is covalently conjugated to a-TNF

The PlGF-2 $123-144$ peptide was covalently conjugated with $\alpha$-TNF using a crosslinker. SDS-PAGE revealed that the molecular weights of both the light and heavy chains of $\alpha$-TNF were increased (Fig. 1a). Under the stoichiometric conditions used, the $\alpha$-TNF bound approximately 4.2 PlGF- 2 123-144 peptides per antibody (average $13.4 \mathrm{kDa}$ shift) as measured by MALDI-TOF MS (Fig. 1b). We have previously reported that multiple PlGF-2 123-144 peptides are conjugated to an IgG under the same reaction conditions [24], suggesting that this reaction is unaffected by antibody clones.

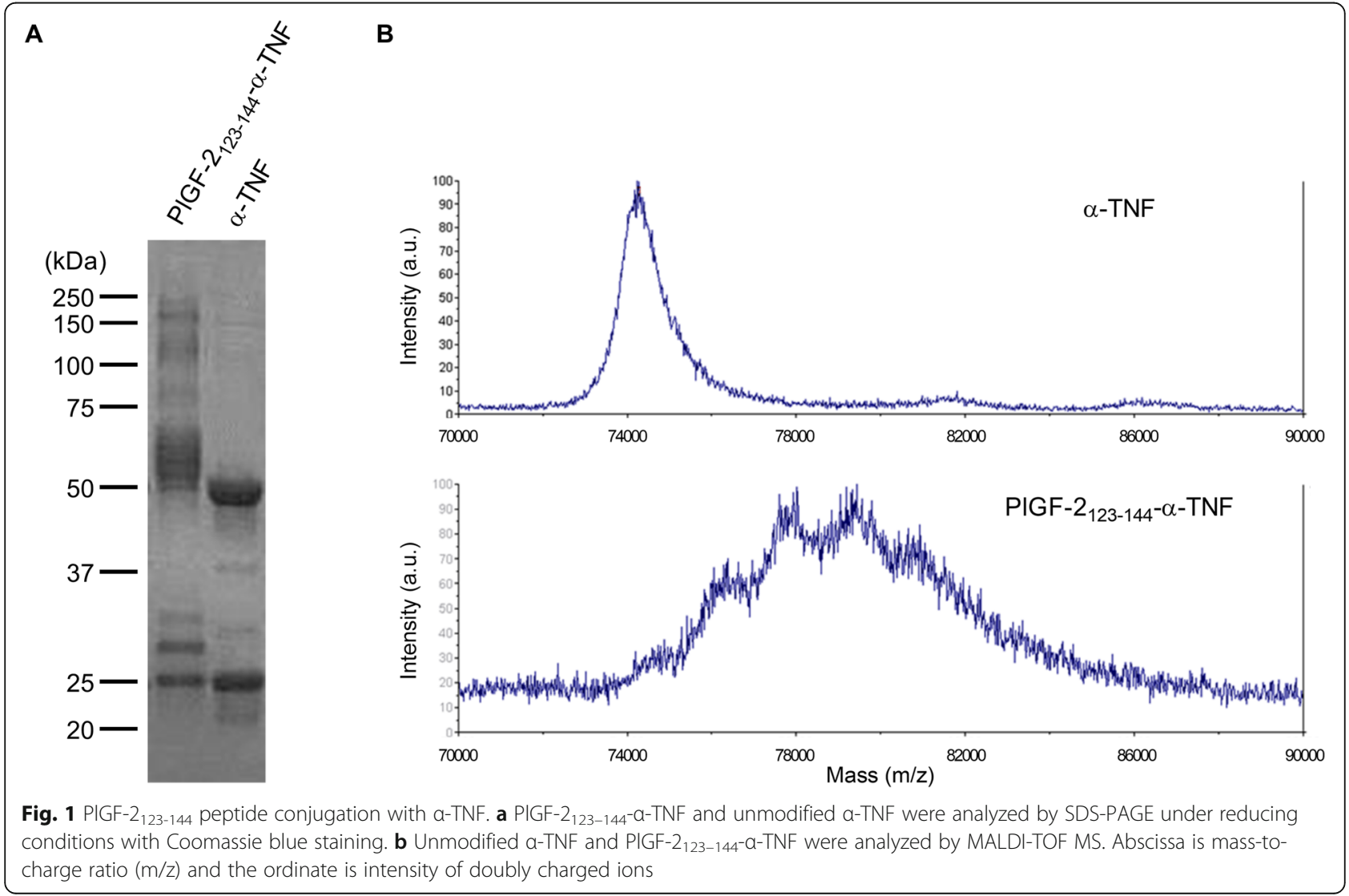


PIGF-2 ${ }_{123-144}$-a-TNF binds to multiple ECM proteins with high affinity

The effect of PlGF-2 123 -144 peptide conjugation on the binding activity of $\alpha-T N F$ against ECM proteins was tested by ELISA. PIGF-2 $123-144^{-\alpha-T N F}$ was shown to bind to all tested ECM proteins, namely fibronectin, decorin, collagen I, collagen II, collagen III, and collagen IV; whereas no binding signal of unmodified $\alpha$-TNF to these ECM proteins was detectable (Fig. 2A). In addition, PlGF-2 $123-144-\alpha-T N F$ bound to ECM proteins in human cartilage specimens from an OA patient. The specimen was probed with either unmodified $\alpha$-TNF or PlGF2 123-144- $\alpha$-TNF, together with antibodies against cartilage components, namely collagen II and decorin. PlGF$2{ }_{123-144}-\alpha$-TNF bound to the regions where collagen II and decorin are rich, whereas binding of unmodified $\alpha$ TNF was not detected (Fig. 2b). These data indicate that PlGF-2 123-144-conjugation provided $\alpha$-TNF with affinity against ECM proteins in cartilage.

\section{PIGF-2 ${ }_{123-144}$ conjugation to a-TNF did not impair antibody neutralizing ability}

We tested the effect of the PlGF-2 ${ }_{123-144}$ conjugation on antigen recognition by $\alpha$-TNF. PlGF- $2123-144^{-} \alpha-T N F$ bound to TNF $\alpha$ similarly to the unmodified antibody as determined by ELISA (Fig. 3a). The values of the slope (95\% confidence interval $[\mathrm{CI}])$ of the regression lines were $0.74(0.57-0.90)$ for unmodified $\alpha$-TNF and $0.82(0.55-1.10)$ for PIGF2 123-144- $\alpha$-TNF. We further investigated the activity of PIGF-2 $123-144^{-} \alpha$-TNF and unmodified $\alpha$-TNF in vitro using

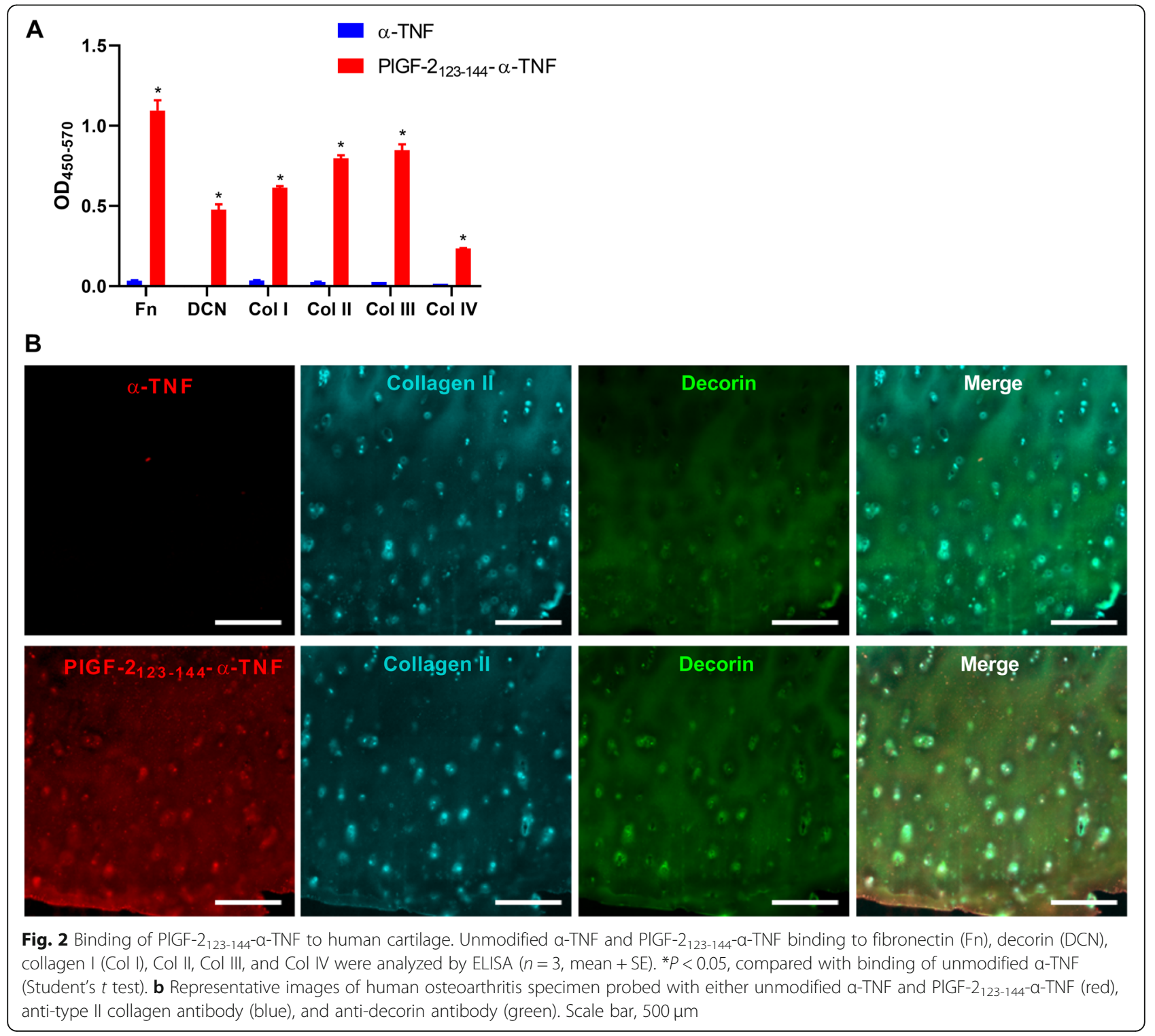




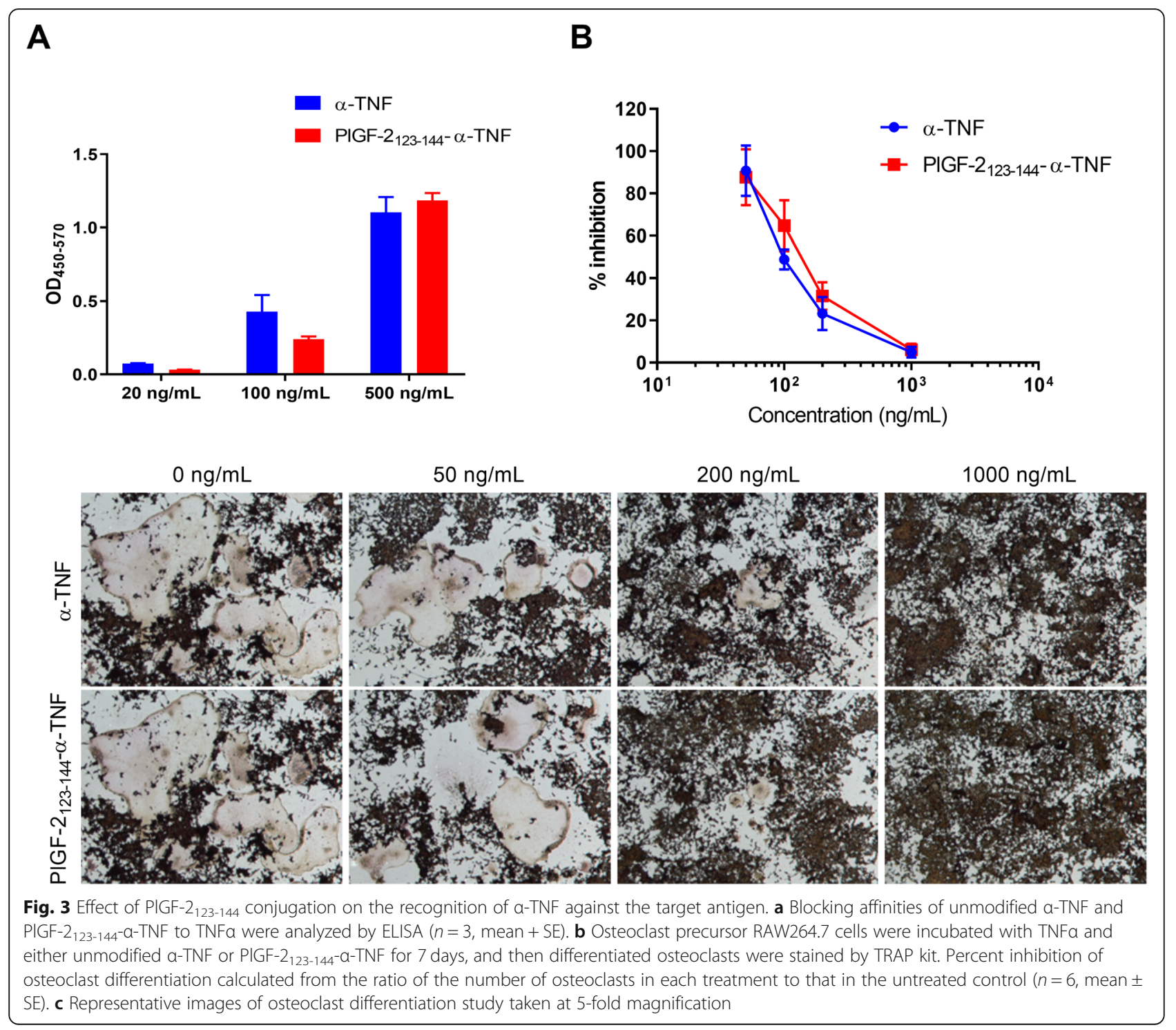

an assay of osteoclast differentiation, which are induced in response to TNF $\alpha$ from the osteoclast precursor RAW264.7 cells [27]. RAW264.7 cells were incubated with TNF $\alpha$ and either unmodified $\alpha$-TNF or PlGF-2 $123-144^{-} \alpha-T N F$ for 7 days, and then the number of differentiated osteoclasts was determined. Osteoclast differentiation was suppressed by both antibodies in a similar manner (Fig. $3 \mathrm{~b}, \mathrm{c}$ ). The $\mathrm{IC}_{50}$ values (95\% CI) of unmodified $\alpha$-TNF and PlGF-2 $2_{123-144^{-} \alpha-\mathrm{TNF}}$ were $98(87-113) \mathrm{ng} / \mathrm{mL}$ and $128(108-155) \mathrm{ng} / \mathrm{mL}$, respectively. These data indicate that PlGF-2 ${ }_{123-144}$ conjugation provided $\alpha$-TNF with affinity against ECM proteins, with limited impairment of its function.

PIGF-2 ${ }_{123-144-a-T N F}$ retention is prolonged at the injected paw

Retention of PlGF-2 $123-144-\alpha-T N F$ at the injection site was determined by in vivo bio-distribution analysis in
CAIA mice. Fluorescently labeled $\alpha-T N F$ or PlGF$2123-144^{-\alpha-T N F}$ was injected at the left hind footpad of CAIA mice on the day following arthritis induction by LPS. Whole-body fluorescence was measured immediately after the injection, and $0.5,1,2,3,24,48,96$, and $168 \mathrm{~h}$ after the injection (Fig. 4). The fluorescence level was detected at the injected paw, and retention of $\alpha$ TNF at the injected paw was reduced immediately after the injection. To the contrary, the fluorescence of PlGF$2{ }_{123-144-\alpha-T N F}$ was maintained at a higher level at the injected paw and was detectable until $96 \mathrm{~h}$ after the injection. We also investigated the bio-distribution using athymic nude mice. The fluorescence of PlGF- $2_{123-144^{-} \alpha-}$ TNF was detected only at the injected paw until $96 \mathrm{~h}$ after the injection and the retention of PlGF-2 $23-144^{-\alpha} \alpha-$ TNF was significantly greater than unmodified $\alpha$-TNF (Additional file 1: Figure S1). These data suggest that 


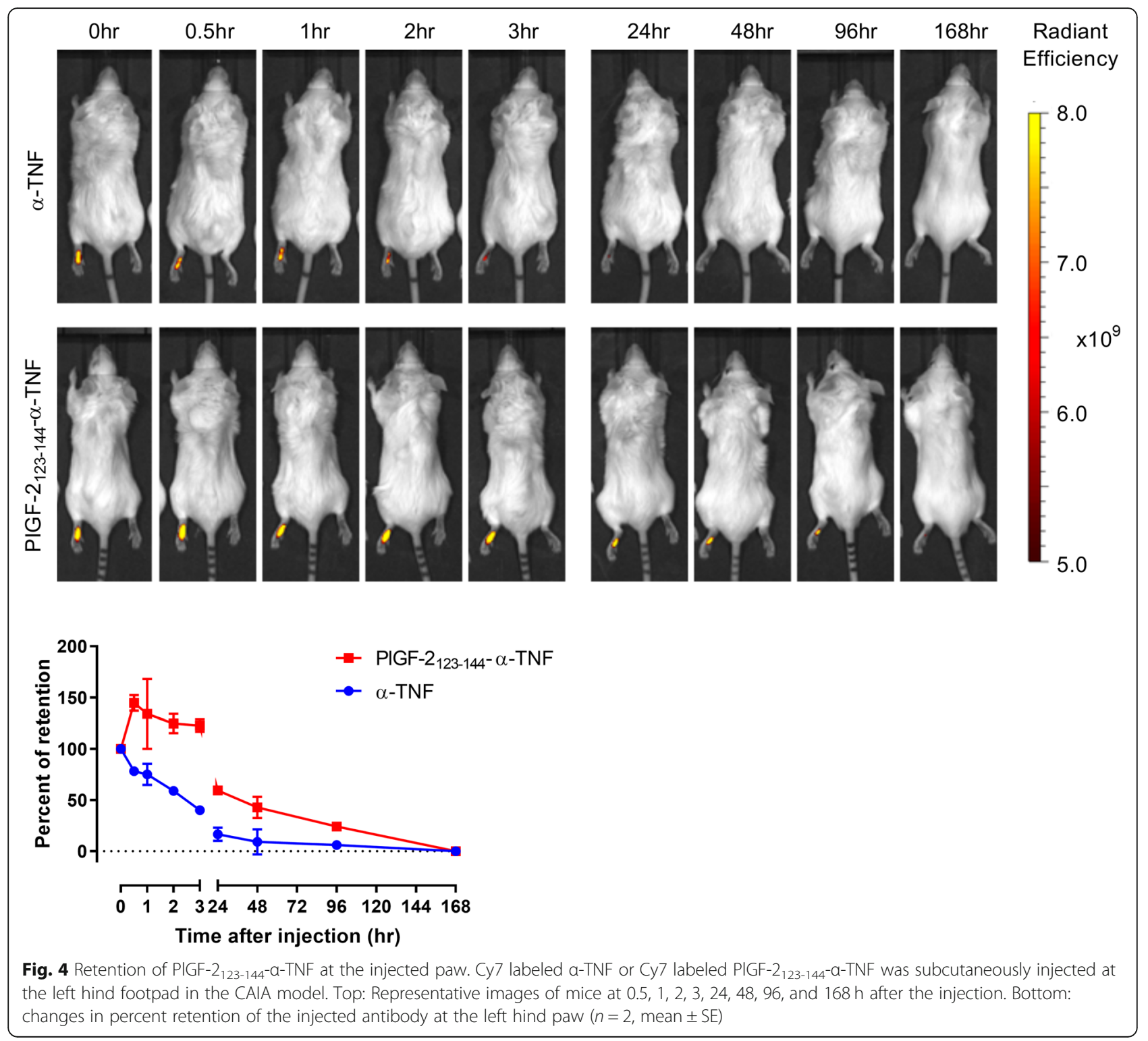

PlGF-2 $123-144^{-\alpha-T N F}$ binds to ECM proteins and is retained at the injection site.

\section{Locally injected PIGF-2 $123-144-a-T N F$ suppressed RA} development almost completely in the CAIA model To examine the therapeutic efficacy of PlGF- $2_{123-144^{-}} \alpha-$ TNF, control IgG $(100 \mu \mathrm{g})$, unmodified $\alpha$-TNF $(100 \mu \mathrm{g})$, or PlGF-2 $123-144^{-} \alpha-\mathrm{TNF}(1 \mu \mathrm{g})$ was injected at the left hind footpad of CAIA mice (Fig. 5). The arthritis score was increased in both the right and left hind paws in control IgG-treated mice. Unmodified $\alpha$-TNF did not suppress the score in this treatment regimen. PlGF2123-144- $\alpha$-TNF; however, suppressed arthritis development almost completely in the treated paw even at a $100 \times$ lower dose than unmodified $\alpha$-TNF. PIGF-2 $123-144^{-}$ $\alpha$-TNF did not suppress arthritis development in the untreated paw, indicating its localized efficacy. We also confirmed that PlGF-2 $123-144$ peptide in itself did not suppress arthritis development (Additional file 1: Figure S2), and that in contrast to unmodified $\alpha-T N F$, PlGF-2 123-144- $\alpha$-TNF was not detected in plasma (Additional file 1: Figure S3). Moreover, we examined the efficacy of PlGF-2 $123-144-\alpha-T N F$ at $10 \times$ further lower dose. PlGF-2 $123-144-\alpha-T N F$ even at $0.1 \mu \mathrm{g}$ completely suppressed the arthritis score at the treated paw (Fig. 6a), and joint histology in the treated paw appeared normal, whereas synovial proliferation, leukocyte infiltration, and cartilage degeneration were observed in untreated control joint (Fig. 6b). These data demonstrate that locally injected PlGF-2 $123-144^{-} \alpha-$ TNF induces robust improvement of RA therapy without systemic exposure. 

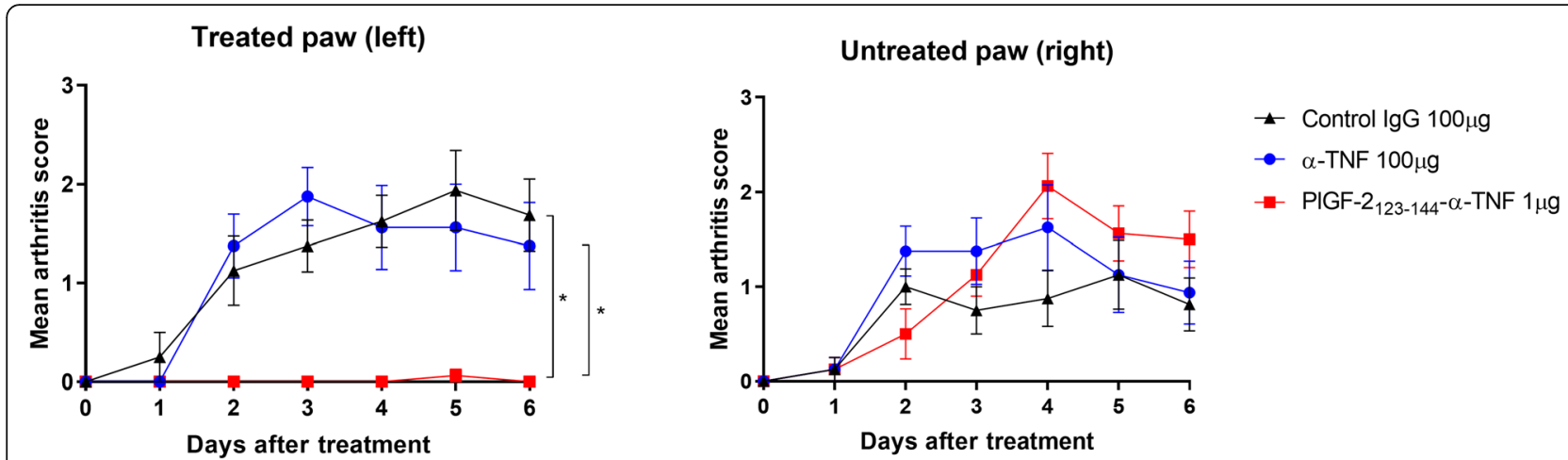

Fig. 5 Effect of PIGF-2 $123-144-$ a-TNF locally injected around joints of the CAIA model. Arthritis was induced by intraperitoneal injection of anticollagen antibodies, followed by intraperitoneal injection of LPS. On the day of LPS injection, isotype control lgG (100 $\mu g)$, unmodified a-TNF $(100 \mu \mathrm{g})$, or PIGF-2 $123-144^{-a-T N F}(1 \mu \mathrm{g})$ was subcutaneously injected into the left hind paw of the CAIA mice. Arthritis scores of the treated paw and the untreated paw represent the mean \pm SE from 8 mice. ${ }^{*} P<0.05$, compared with the scores on day 6 of each group (Tukey's multiple comparison test)

\section{Discussion}

Interest in clinical translation of intra-articularly administered therapies is growing rapidly [28]. Systemic administration of bio-therapeutics can result in only a fraction of the drug reaching the targeted tissues, with the majority of the drug being distributed to tissues irrelevant to the drug's site of action. Localized therapy may allow for greater accumulation at target sites, better efficacy, and improved safety. Therefore, local injection is a reasonable approach for patients with monoarthritis or oligoarthritis who do not necessarily need to be exposed to systemic $\alpha$-TNF treatment. In many cases, polyarthritic disorders initially present as a monoarthritis, which is potentially locally treatable. In this study, we demonstrate that PlGF-2 ${ }_{123-144}$ peptide conjugation enhanced the local efficacy of $\alpha$-TNF by at least $1000 \times$ based on dose-comparison and that the therapeutic efficacy was robust. This demonstrates that PlGF2123-144 peptide conjugation enables $\alpha$-TNF to be retained at joints to block TNF $\alpha$ signaling thoroughly and enhance its potency. Significant reduction of the effective dose and corresponding systemic exposure of locally-administered PlGF-2 ${ }_{123-144-\alpha-T N F}$ suggests that this technology may help avoid unnecessary exposure of $\alpha$-TNF to the whole body, with a corresponding reduction in adverse events.

PIGF-2 $123-144^{-} \alpha-T N F$ showed high efficacy when injected at the paw. Since the mouse paw contains many joints and disease scoring in a single joint over time is difficult, in this study we injected drugs nearby the joint space. PIGF-2 $123-144^{-} \alpha-$ TNF binds strongly to ECM proteins including collagen II, i.e., major components of cartilage and synovium, and was retained at the injection site. Therefore, these data support the concept that that

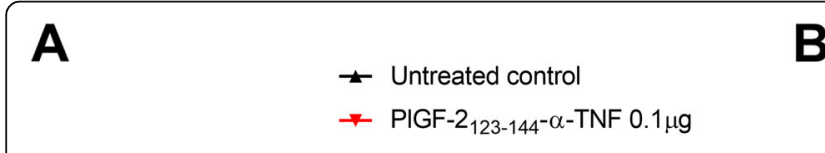

B
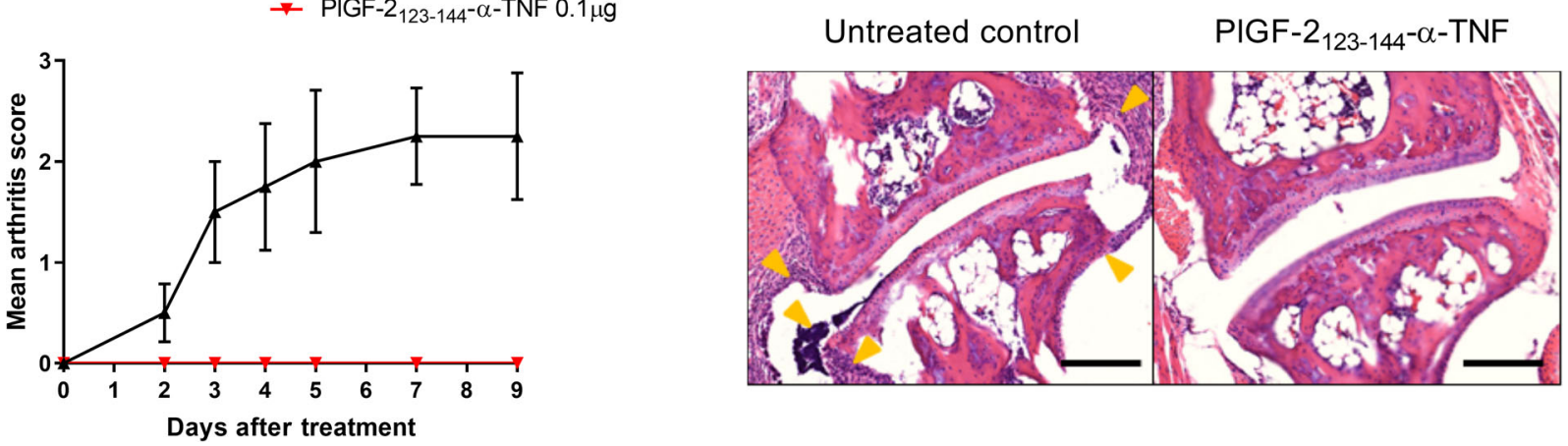

Fig. 6 Effect of PIGF-2 $123-144^{-a-T N F}$ in joint destruction of the arthritis model. Arthritis was induced by intraperitoneal injection of anti-collagen antibodies, followed by intraperitoneal injection of LPS. On the day of LPS injection, PIGF-2123-144-a-TNF $(0.1 \mu g)$ was subcutaneously injected into the left hind paw of the CAIA mice. a Arthritis scores of the treated paw represent the mean \pm SE from 4 mice. $\mathbf{b}$ Representative H\&E image of joints on day 9 in the untreated control (left) and PIGF-2123-144-a-TNF-treated group (right). Arrows indicate cellular infiltrations. Scale bars, $200 \mu \mathrm{m}$ 


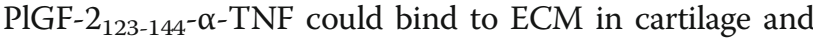
the synovium before draining from lymphatic vessels even

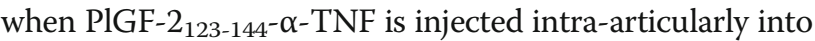
the joint, although further evaluation of intra-articular injection using larger animals is warranted.

Various technologies have been proposed to achieve prolonged retention of locally injected drugs, such as particle- or liposome-based drug delivery systems and modification by polypeptide conjugation [28]. Although these technologies prolong the intra-articular residence time of biologic drugs [29-31], these approaches only slightly reduced systemic circulation and there is no report to show clearly their enhanced therapeutic efficacy against disease symptoms. Therefore, our data suggest a novel approach of tissue retention of $\alpha$-TNF to efficiently and locally treat RA and reduce systemic exposure due to dose reduction.

For clinical translation of ECM-binding antiinflammatory bio-therapeutics, an advantage also lies in the use of the PIGF-2 $123-144$ peptide, which naturally exists in the human body as a domain on PlGF, limiting the possibility of recognition by the immune system. It was confirmed that the PlGF-2 ${ }_{123-144}$ peptide-conjugated antibody was capable of binding with human ECM proteins and human specimens. Also, the PlGF-2 $2_{123-144}$ peptide can be conjugated to antibodies with a simple chemical reaction. The advantage of this feature is in the simplicity in production, in that it is possible to work with antibodies for which production has already been optimized. The PlGF2123-144 peptide conjugation synthesis reaction for antibodies can be accomplished using chemistry that is analogous to PEGylation of proteins. Indeed, the same chemical reaction is used in antibody-drug conjugates, such as in the production of trastuzumab emtansine. These features may facilitate the development of ECM binding-drug therapy to overcome the barriers to clinical translation.

\section{Conclusions}

We have found that installing an ECM-binding affinity to $\alpha$-TNF enables it to be retained at the injection site. Moreover, ECM-binding $\alpha$-TNF showed robust therapeutic efficacy in a mouse model of RA at a very low dose. This simple approach of generating an engineered ECM-binding $\alpha$-TNF bio-therapeutic may hold potential for clinical translation as a local anti-inflammatory therapeutic in RA.

\section{Supplementary information}

Supplementary information accompanies this paper at https://doi.org/10. 1186/s13075-019-2075-8

Additional file 1: Figure S1. Retention of PIGF-2 $123-144^{-a-T N F}$ at the injected paw of athymic nude mice. Figure S2. Effect of PIGF-2123-144 peptide locally injected around joints of the CAIA model. Figure S3. Changes in plasma concentrations after local injection to CAIA mice.

\section{Abbreviations}

AUC: Area under the curve; CAIA: Collagen antibody-induced arthritis model Cy7: Cyanine 7; ECM: Extracellular matrix; GF: Growth factors; HBD: Heparinbinding domain; HRP: Horseradish peroxidase; LPS: Lipopolysaccharides; MALDI-TOF MS: Matrix-assisted laser desorption/ionization-time-of-flight mass spectrometry; PBS: Phosphate-buffered saline; PBS-T: 2\% BSA in PBS with $0.05 \%$ Tween 20; PIGF-2 123-144: HBD of placenta growth factor-2; PIGF2123-144-a-TNF: PIGF-2 123-144-conjugated a-TNF; RA: Rheumatoid arthritis; SDSPAGE: Sodium dodecyl sulfate-polyacrylamide gel electrophoresis; a-

TNF: Anti-tumor necrosis factor-a antibody

\section{Acknowledgements}

We thank the Human Tissue Resource Center of the University of Chicago for histology analysis. We thank the Integrated Light Microscopy Core of the University of Chicago for Imaging. We thank J. Paz-Montoya and M. Moniatte for MALDI-TOF analysis in the Proteomics Core Facility of the Ecole Polytechnique Fédérale de Lausanne (EPFL), Switzerland.

Authors' contributions

$\mathrm{KK}, \mathrm{Jl}$, and JAH designed the project. KK, JI, KF, Al, EY, and EB performed experiments. KK, Jl, KF, and JAH analyzed data. KK, Jl, and JAH wrote the paper. All authors read and approved the final manuscript.

Funding

This work was supported by the University of Chicago (to J.A.H.).

Availability of data and materials

All data generated or analyzed during this study are included in this article and its supplementary information files.

\section{Ethics approval}

All the animal experiments performed in this work were approved by the Institutional Animal Care and Use Committee of the University of Chicago.

\section{Consent for publication}

N/A

\section{Competing interests}

KK, JI, Al, and JAH are inventors on U.S. Provisional Patent application 62/ 809,988 . The other authors declare that they have no competing interests.

\section{Author details}

${ }^{1}$ Pritzker School of Molecular Engineering, University of Chicago, Chicago, IL 60637, USA. ${ }^{2}$ Present Address: Astellas Pharma Inc., Tsukuba, Ibaraki 305-8585, Japan. ${ }^{3}$ Present Address: FUJIFILM Corporation, Kanagawa 258-8577, Japan. ${ }^{4}$ Department of Applied Chemistry, Osaka Prefecture University, Osaka 599-8531, Japan. ${ }^{5}$ Committee on Immunology, University of Chicago, Chicago, IL 60637, USA.

Received: 18 July 2019 Accepted: 29 November 2019

Published online: 23 December 2019

References

1. Firestein GS. Evolving concepts of rheumatoid arthritis. Nature. 2003; 423(6937):356-61.

2. Mclnnes IB, Schett $G$. The pathogenesis of rheumatoid arthritis. N Engl J Med. 2011;365(23):2205-19.

3. Moreland LW, Schiff MH, Baumgartner SW, Tindall EA, Fleischmann RM, Bulpitt KJ, Weaver AL, Keystone EC, Furst DE, Mease PJ, et al. Etanercept therapy in rheumatoid arthritis. A randomized, controlled trial. Ann Intern Med. 1999;130(6):478-86.

4. Maini R, St Clair EW, Breedveld F, Furst D, Kalden J, Weisman M, Smolen J, Emery $P$, Harriman G, Feldmann $M$, et al. Infliximab (chimeric anti-tumour necrosis factor alpha monoclonal antibody) versus placebo in rheumatoid arthritis patients receiving concomitant methotrexate: a randomised phase III trial. ATTRACT Study Group. Lancet. 1999:354(9194):1932-9.

5. Weinblatt ME, Keystone EC, Furst DE, Moreland LW, Weisman MH, Birbara CA, Teoh LA, Fischkoff SA, Chartash EK. Adalimumab, a fully human antitumor necrosis factor alpha monoclonal antibody, for the treatment of rheumatoid arthritis in patients taking concomitant methotrexate: the ARMADA trial. Arthritis Rheum. 2003:48(1):35-45. 
6. Nishimoto N, Yoshizaki K, Miyasaka N, Yamamoto K, Kawai S, Takeuchi T, Hashimoto J, Azuma J, Kishimoto T. Treatment of rheumatoid arthritis with humanized anti-interleukin-6 receptor antibody: a multicenter, double-blind, placebo-controlled trial. Arthritis Rheum. 2004;50(6):1761-9.

7. Bongartz T, Sutton AJ, Sweeting MJ, Buchan I, Matteson EL, Montori V. AntiTNF antibody therapy in rheumatoid arthritis and the risk of serious infections and malignancies: systematic review and meta-analysis of rare harmful effects in randomized controlled trials. JAMA. 2006;295(19):2275-85.

8. Dixon WG, Hyrich KL, Watson KD, Lunt M, Galloway J, Ustianowski A, Consortium BSRBRCC, Symmons DP, Register BSRB. Drug-specific risk of tuberculosis in patients with rheumatoid arthritis treated with anti-TNF therapy: results from the British Society for Rheumatology Biologics Register (BSRBR). Ann Rheum Dis. 2010;69(3):522-8.

9. Bellis E, Scire CA, Carrara G, Adinolfi A, Batticciotto A, Bortoluzzi A, Cagnotto G, Caprioli M, Canzoni M, Cavatorta FP, et al. Ultrasound-detected tenosynovitis independently associates with patient-reported flare in patients with rheumatoid arthritis in clinical remission: results from the observational study STARTER of the Italian Society for Rheumatology. Rheumatology (Oxford). 2016;55(10):1826-36.

10. Lisbona MP, Solano A, Ares J, Almirall M, Salman-Monte TC, Maymo J. ACR/ EULAR definitions of remission are associated with lower residual inflammatory activity compared with DAS28 remission on hand MRI in rheumatoid arthritis. J Rheumatol. 2016:43(9):1631-6.

11. Vreju FA, Filippucci E, Gutierrez M, Di Geso L, Ciapetti A, Ciurea ME, Salaffi F, Grassi W. Subclinical ultrasound synovitis in a particular joint is associated with ultrasound evidence of bone erosions in that same joint in rheumatoid patients in clinical remission. Clin Exp Rheumatol. 2016;34(4):673-8.

12. Mjaavatten MD, Haugen AJ, Helgetveit $K$, Nygaard H, Sidenvall G, Uhlig T, Kvien TK. Pattern of joint involvement and other disease characteristics in 634 patients with arthritis of less than 16 weeks' duration. J Rheumatol. 2009;36(7):1401-6.

13. Jones G, Nash P, Hall S. Advances in rheumatoid arthritis. Med J Aust. 2017: 206(5):221-4.

14. Bajpayee AG, Grodzinsky AJ. Cartilage-targeting drug delivery: can electrostatic interactions help? Nat Rev Rheumatol. 2017;13(3):183-93.

15. Wallis WJ, Simkin PA, Nelp WB. Protein traffic in human synovial effusions. Arthritis Rheum. 1987;30(1):57-63.

16. Bliddal H, Terslev L, Qvistgaard E, Konig M, Holm CC, Rogind H, Boesen M, Danneskiold-Samsoe B, Torp-Pedersen S. A randomized, controlled study of a single intra-articular injection of etanercept or glucocorticosteroids in patients with rheumatoid arthritis. Scand J Rheumatol. 2006;35(5):341-5.

17. Aalbers C, Gerlag D, Vos K, Vervoordeldonk M, Landewe R, Tak PP. Intraarticular etanercept treatment in inflammatory arthritis: a randomized double-blind placebo-controlled proof of mechanism clinical trial validating TNF as a potential therapeutic target for local treatment. Joint Bone Spine. 2015;82(5):338-44.

18. Martino MM, Briquez PS, Ranga A, Lutolf MP, Hubbell JA. Heparin-binding domain of fibrin (ogen) binds growth factors and promotes tissue repair when incorporated within a synthetic matrix. Proc Natl Acad Sci U S A. 2013;110(12):4563-8.

19. Martino MM, Tortelli F, Mochizuki M, Traub S, Ben-David D, Kuhn GA, Muller R, Livne E, Eming SA, Hubbell JA. Engineering the growth factor microenvironment with fibronectin domains to promote wound and bone tissue healing. Sci Transl Med. 2011;3(100):100ra189.

20. De Laporte L, Rice JJ, Tortelli F, Hubbell JA. Tenascin C promiscuously binds growth factors via its fifth fibronectin type III-like domain. PLoS One. 2013; 8(4):e62076.

21. Tortelli F, Pisano M, Briquez PS, Martino MM, Hubbell JA. Fibronectin binding modulates CXCL11 activity and facilitates wound healing. PLOS One. 2013;8(10):e79610.

22. Maile LA, Busby WH, Sitko K, Capps BE, Sergent T, Badley-Clarke J, Ling Y, Clemmons DR. The heparin binding domain of vitronectin is the region that is required to enhance insulin-like growth factor-I signaling. Mol Endocrinol. 2006;20(4):881-92.

23. Martino MM, Briquez PS, Guc E, Tortelli F, Kilarski WW, Metzger S, Rice JJ, Kuhn GA, Muller R, Swartz MA, et al. Growth factors engineered for superaffinity to the extracellular matrix enhance tissue healing. Science. 2014; 343(6173):885-8.

24. Ishihara J, Fukunaga K, Ishihara A, Larsson HM, Potin L, Hosseinchi P, Galliverti G, Swartz MA, Hubbell JA: Matrix-binding checkpoint immunotherapies enhance antitumor efficacy and reduce adverse events. Sci Transl Med. 2017;9(415):eaan0401.

25. Ishihara J, Ishihara A, Potin L, Hosseinchi P, Fukunaga K, Damo M, Gajewski TF, Swartz MA, Hubbell JA. Improving efficacy and safety of agonistic antiCD40 antibody through extracellular matrix affinity. Mol Cancer Ther. 2018; 17(11):2399-411.

26. Kagari T, Doi H, Shimozato T. The importance of IL-1 beta and TNF-alpha, and the noninvolvement of IL-6, in the development of monoclonal antibody-induced arthritis. J Immunol. 2002;169(3):1459-66.

27. Kobayashi K, Takahashi N, Jimi E, Udagawa N, Takami M, Kotake S, Nakagawa N, Kinosaki M, Yamaguchi K, Shima N, et al. Tumor necrosis factor alpha stimulates osteoclast differentiation by a mechanism independent of the ODF/RANKL-RANK interaction. J Exp Med. 2000;191(2):275-86.

28. Evans $\mathrm{CH}$, Kraus VB, Setton LA. Progress in intra-articular therapy. Nat Rev Rheumatol. 2014:10(1):11-22.

29. Erdemli O, Ozen S, Keskin D, Usanmaz A, Batu ED, Atilla B, Tezcaner A. In vitro evaluation of effects of sustained anti-TNF release from MPEG-PCLMPEG and PCL microspheres on human rheumatoid arthritis synoviocytes. J Biomater Appl. 2014;29(4):524-42.

30. Betre H, Liu W, Zalutsky MR, Chilkoti A, Kraus VB, Setton LA. A thermally responsive biopolymer for intra-articular drug delivery. J Control Release. 2006;115(2):175-82.

31. Kimmerling KA, Furman BD, Mangiapani DS, Moverman MA, Sinclair SM, Huebner JL, Chilkoti A, Kraus VB, Setton LA, Guilak F, et al. Sustained intraarticular delivery of IL-1RA from a thermally-responsive elastin-like polypeptide as a therapy for post-traumatic arthritis. Eur Cell Mater. 2015;29: 124-39 discussion 139-140.

\section{Publisher's Note}

Springer Nature remains neutral with regard to jurisdictional claims in published maps and institutional affiliations.
Ready to submit your research? Choose BMC and benefit from:

- fast, convenient online submission

- thorough peer review by experienced researchers in your field

- rapid publication on acceptance

- support for research data, including large and complex data types

- gold Open Access which fosters wider collaboration and increased citations

- maximum visibility for your research: over $100 \mathrm{M}$ website views per year

At $\mathrm{BMC}$, research is always in progress.

Learn more biomedcentral.com/submissions 